\title{
Universidad de Medellín \\ Justicia transicional: \\ Noción de la justicia en la transición colombiana
}

\author{
Francisco Javier Valderrama Bedoya** \\ Marvin Octavio Ortiz Agudelo*** \\ DOI: 10.22395/ojum.v16n32al1
}

\section{RESUMEN}

Se tratará de considerar si la justicia transicional es el mecanismo más eficaz para aplicar legalmente en el fin del conflicto armado interno entre el Estado colombiano y las Fuerzas Armadas Revolucionarias Colombianas -FARC-. En ese sentido, se estudiaron varias concepciones de justicia a lo largo de la historia y cómo unas de ellas sirvieron como referente para algunos casos bélicos que fueron resueltos por tribunales internacionales. Se analizará cómo debe entenderse la justicia transicional por los interesados en la superación de un conflicto y permitir con ello el tránsito a una mejor convivencia en Colombia. Lo anterior llevó a estudiar si este término es un concepto sui géneris y autónomo de justicia, una idea de justicia que se enmarca dentro de otro concepto de lo justo o, por último, si la justicia de transición es un concepto sincrético, donde convergen varias ideas de justicia. El resultado es que la justicia transicional, en el caso colombiano, es sinónimo de alternativa evolutiva transitoria para solucionar un problema en concreto, es decir, la justicia transicional colombiana no es un mecanismo jurídico permanente, es un instrumento innovador transitorio que ayuda a evolucionar la aplicación del derecho en el sentido que sirve solo para resolver un problema como el conflicto interno armado que se vivió por más de 50 años entre el Estado y las FARC. Se concluye que la justicia transicional está compuesta por variedad de ideas de justicia que se complementan para hacer frente a una realidad social y proporcionan un horizonte teórico para lograr un tránsito social hacia la reconciliación.

Palabras clave: Justicia; justicia transicional; convivencia; paz

\footnotetext{
Este trabajo es producto del proyecto de investigación "La proporcionalidad como método interpretativo de la justicia transicional" adscrito a la Maestría en Derechos Humanos y Derecho Internacional Humanitario de la Universidad de Medellín. Elaborado entre enero a junio de 2017.

* Licenciado en Filosofía y magíster en Filosofía, de la Universidad Pontificia Bolivariana, Medellín, Colombia; abogado, magíster en Derecho y doctor en Derecho de la Universidad de Medellín, Medellín, Colombia. Decano de la Facultad de Derecho de la Universidad de Medellín, Medellín, Colombia. Contacto: fjvalderrama@ udem.edu.co

** Abogado y especialista en Derecho Administrativo de la Universidad Pontificia Bolivariana, Medellín, Colombia, y candidato a magíster en Derechos Humanos y Derecho Internacional Humanitario de la Universidad de Medellín, Medellín, Colombia. Contacto: marvin.ortiz.a@gmail.com
} 


\section{Transitional justice: the notion of justice in the Colombian transition} ABSTRACT

If transitional justice is the most effective mechanism to legally apply to the end of the internal armed conflict between the Colombian State and the Revolutionary Armed Forces of Colombia (FARC) will be considered, having as a reference several conceptions of justice studied throughout history and how some of them served as references for some war cases resolved by international tribunals. How transitional justice should be understood by those interested in overcoming a conflict and thus allow the transition to a better coexistence in Colombia will be analyzed. This led us to study whether this term is a sui generis and autonomous concept of justice, an idea of justice that is framed within another concept of the fair or, finally, whether transitional justice is a syncretic concept, where various ideas of justice converge. In Colombia, transitional justice is a synonym of a transitional evolutionary alternative to solve a specific problem. Colombian transitional justice is not a permanent legal mechanism, it is an innovative transitional instrument helping to evolve the application of law to solve a problem: the internal armed conflict experience for more than 50 years. It concludes that transitional justice is composed by several ideas of justice complementing each other dealing with social reality and providing a theoretical horizon for achieving a social transition to reconciliation.

Keywords: Justice; transitional justice; coexistence; peace.

\section{Justiça de transição: noç̃ão da justiça na transição colombiana RESUMO}

Este texto trata de considerar se a justiça de transição é o mecanismo mais eficaz para aplicar legalmente no fim do conflito armado interno entre o Estado colombiano e as Forças Armadas Revolucionárias Colombianas (Farc). Nesse sentido, foram estudados conceitos de justiça ao longo da história e como uma delas serviu de referente para alguns casos bélicos que foram resolvidos por tribunais internacionais. Analisa-se como a justiça de transição deve ser entendida pelos interessados na superação de um conflito e, com isso, permitir-se a transição a uma melhor convivência na Colômbia. O anterior levou a estudar se esse termo é um conceito sui géneris e autônomo de justiça, uma ideia de justiça que está delimitada em outro conceito do justo ou, por último, se a justiça de transição é um conceito sincrético, em que convergem várias ideias de justiça. O resultado demonstrou que a justiça de transição, no caso colombiano, é sinônimo de alternativa evolutiva transitória para solucionar um problema em concreto, isto é, a justiça de transição colombiana não é um mecanismo jurídico permanente, é um instrumento inovador transitório que ajuda a evoluir a aplicação do direito no sentido que serve somente para resolver um problema como o conflito interno armado, que se viveu por mais de 50 anos entre o Estado e as Farc. Conclui-se que a justiça de transição está composta por ideias que se complementam para enfrentar uma realidade social e proporcionam um horizonte teórico para atingir uma transição social rumo à reconciliação.

Palavras-chave: convivência; justiça; justiça de transição; paz. 


\section{INTRODUCCIÓN}

La justicia es un término que ha sido discutido en gran parte de la historia de la humanidad. El ser humano, en su relación con los demás, fue descubriendo que el concepto de justicia era necesario en las relaciones sociales, las cuales, dependiendo de la cultura, formulan una justicia acorde a sus necesidades.

En ese sentido, el concepto de justicia es de contenido subjetivo y contextual, vinculado estrechamente al actuar ético y a las convicciones morales de la sociedad y sus individuos. Por ello, incluso las nociones más idealistas de justicia que pretenden ser absolutas responden a mutables criterios axiológicos que gobiernan al individuo o a la sociedad. Por consiguiente, en el contexto actual el alcance del concepto de justicia no puede pretender absolutismo, sería un conato que solo podría acercarse a la consumación si se atiende la relatividad de las circunstancias.

Por lo tanto, para estudiar el significado de la justicia es necesario analizar cómo concibe una sociedad el sentido que debe tener la ley y su fuerza vinculante. También, cómo debe organizarse la sociedad, cómo tratar a sus individuos, descubrir si se da más relevancia a la libertad, al bienestar o a la virtud; todas estas ideas asientan maneras diferentes de concebir la justicia.

De ser así, para comprender el concepto de justicia transicional, entonces debemos atender previamente el concepto genérico de justicia, y analizar si aquel concepto especial hace parte de las tipologías que históricamente se han estudiado o resulta ser un concepto sui géneris o uno sincrético.

A este fin se llegará mediante un estudio heurístico, histórico, documental, donde se analizan las fuentes formales y materiales del derecho. Se estudian, en un primer momento, los conceptos de justicia desde la óptica de la filosofía política, estos son conceptos ideales, aplicables a las democracias. Seguido del concepto de justicia transicional en fuentes de derecho internacional, tales como las Naciones Unidas y la Corte Interamericana de Derechos Humanos; como en la doctrina internacional, producto de esto se delimita y concreta el concepto de lo que se entiende internacionalmente por justicia transicional para luego estudiar la idea de justicia que emana de la justicia transicional, enfrentándola a las ideas genéricas de justicia expuestas en el primer capítulo, para, de este modo, concluir si la justicia transicional es autónoma a las ideas preconcebidas de justicia, se enmarca en una de ellas o se estructura de varios conceptos de justicia que son puestos en práctica para el proceso político-social de justicia transicional. Por último, se hace una propuesta hermenéutica para resolver las tensiones que, en el campo de los derechos fundamentales, están inmersas en la justicia de transición.

\section{TIPOLOGÍA DE LA JUSTICIA: ANTECEDENTES HISTÓRICOS}

La creencia en concebir a Dios como propósito de la justicia es la concepción 
más antigua que se conoce, ya que desde antaño se concibió lo divino como justo; los egipcios apreciaban la justicia por establecer el orden y llevar la prosperidad; la diosa Maat, representaba la justicia, la verdad y la armonía cósmica existente desde el origen y que era ideal preservar. También la mitología judeo-cristiana concibe una visión teológica de la justicia. Dios, Yahvé, por medio de Moisés, prodigó a los hombres con sus mandamientos que deberán ser cumplidos: "Así que pongan en práctica todo lo que el Señor su Dios les ha ordenado, sin desviarse de ello para nada, sigan el camino que el Señor su Dios les ha señalado para que les vaya bien y vivan muchos años..." (Santa Biblia, Deuteronomio 5:33) Y los hombres "tendremos justicia cuando cuidemos de cumplir todos estos mandamiento ante Yahvé nuestro Dios, tal como él nos ha ordenado" (Santa Biblia, Deuteronomio 6:25).

Idea similar imperó en la Grecia antigua, quienes divinizaron la justicia en Temis, que encarnaba el orden divino. Temis representa una concepción importante del desarrollo de la teoría de la orientación de la justicia hacia lo divino. A los jueces de la antigua Grecia se les conocía como "los sirvientes de Temis". Durante la barbárica decadencia de los griegos, en la Edad de Hierro, Temis les abandona elevándose al cielo; este acto muestra que la justicia no les pertenecía a los hombres, era una deidad y el actuar humano era justo, solo en cuanto fuera coherente con las proclamas divinas. Se dice en la Ilíada de Homero, que Temis y Zeus tuvieron por hija a Diké, que sería traducida como el derecho subjetivo o la posibilidad de ejercer la justicia.

La etapa cosmológica de la filosofía griega es un ejemplo histórico de la concepción de lo divino como justo, pues reinaba una fe ciega y una cosmovisión humana sincrética ontológico-deontológica. Heráclito, filósofo de aquella época, consecuentemente, sostuvo que "todas las leyes humanas provienen de lo divino" y "Dios [...] es la encarnación de la justicia cósmica" (Russel, 1972, p. 38).

Esta visión deviene en ocaso a causa del cambio filosófico de Grecia, cuando hubo un tránsito de lo cosmológico a lo antropológico, centrando su objeto de reflexión en el ser humano. El sistema anterior fue confrontado por movimientos escépticos jalonados por los sofistas ${ }^{1}$, cuya figura más notable fue Protágoras, quien sostenía: "el hombre es la medida de todas las cosas" (Russel, 1972, p. 74) concepción del homo mensura tiene trascendencia epistemológica y deontológica y demuestra el cambio que marcó el comienzo de una nueva época.

Igual evolución se vivió después de la época medieval, cuando se abrió paso al antropocentrismo, concretado en la Ilustración. Las creaciones científicas y artísticas que fijaban el nuevo rumbo en el ser humano no tardaron y afianzaron

Russel B. (1972) The History of Western Philosophy. p. 73. New York: Simon \& Schuster. The word "sophist" had originally no bad connotation; it meant, as nearly as may be, what we mean by "professor." A Sophist was a man who made his living by teaching young men certain things that, it was thought, would be usefull to them in practical life. 
la llegada de una nueva época. El poeta londinense Alexander Pope (1688-1744) por entonces escribió: "entonces conócete a ti mismo, no supongas a un Dios que investigar; El estudio del hombre es el estudio apropiado de la humanidad".

Por otra parte, comprender lo justo según su concordancia con el Cosmos, lo divino o Dios, constituye una visión teocentrista de la existencia humana. Esta creencia ha fundado figuras de pensamiento como el iusnaturalismo teológico, que en los albores de la Ilustración, marcó una separación de la idea de Dios como director de la justicia y se adecuó a la nueva etapa histórica, donde imperó el racionalismo, asumiendo valores éticos como determinantes de lo justo; ello dio paso al naturalismo racionalista que es independiente del concepto de lo divino, toda vez que la directriz ética estaría presente inclusive etsi deus non daretur (si Dios no existiera). Se considera entonces el fundamento de la justicia en la razón humana, que es apta por sí misma de hallar leyes universales en la naturaleza (Grocio, 1625).

A su vez, este modelo ha sido encauzado en diferentes vertientes. Prominentes filósofos como Aristóteles, Platón, Cicerón, H. Grocio, J. Locke, R. Alexy y escolásticos como Anselmo de Cantenbury, Santo Tomas de Aquino y Gottfried Leibniz, Hegel y Martin Heidegger han propuesto una visión supra convencional de la justicia, encontrándola en deducciones lógicas, empíricas y/o espirituales que pueden estar en concordancia, o no, con las leyes humanas, considerando la ley como el producto de la democracia, del acuerdo de hombres libres que por voluntad escogen un sistema de creencias y valores que consideran deben gobernar el comportamiento social.

Platón, el fundador de la academia en el año 387 a. C., es el filósofo que comienza a hablar sobre la corriente iusnaturalista; de una manera amplia sostiene que el actuar y la ley justa lo son, en cuanto concuerden con la idea de justicia. Fue sucedido por Aristóteles, quien consideró que la justicia natural, por encima de la legal y consuetudinaria, tiene fuerza y vigencia en todo lugar y sin necesidad de ser convenida o positivizada. En su Ética nicomaquea (Libro V cap. VII) Aristóteles sostiene:

\begin{abstract}
Paréceles a algunos que todas las normas son de derecho legal, dando como razón que lo que es por naturaleza es inmutable y tiene dondequiera la misma fuerza, como el fuego, que quema aquí lo mismo que en Persia, mientras que, por el contrario, vemos cambiar las cosas tenidas por justas.
\end{abstract}
[...] Por más que entre los dioses la mudanza tal vez no exista en absoluto, entre nosotros todo lo que es por naturaleza está sujeto a cambio [...] por disposición de la ley, y por convención...

Aristóteles predicaba que la justicia estriba en dar a cada quien lo que se merece. Ahora ¿qué merece cada quién? Para ello, debemos determinar qué virtudes son dignas de recibir honores y recompensas (Sandel, 2013) y qué vicios de recibir 
castigos. Según el filósofo de Estagira, la concepción de justicia es satisfecha por la realización de la idea de lo bueno y de la manera más benéfica de vivir, y concibe las normas como una herramienta o medio para ello. También afirma que para entender la justicia es menester debatir respecto de la virtud, el honor y el buen vivir. Responder a la pregunta sobre qué merece cada quién implica remitirse al asunto especifico y a los sujetos en cuestión, esto es, qué y a quién se le otorgan los bienes. En su libro Política, Aristóteles ejemplifica su posición sobre lo justo al distribuir flautas; supongamos que hay un hombre que a pesar de ser muy diestro para tocar el instrumento, no tuvo favorabilidad en su clase social, tampoco en su belleza. Supóngase que los rivales a los que se enfrenta en la repartición de las flautas lo superan en grado social y en belleza; para el autor de la Política, se "deberá entregar el instrumento más perfecto al artista que más perfectamente sepa servirse de él" (Aristóteles, 1969) sin consideración a ninguna otra circunstancia. Aristóteles cree que "todas las ciencias, todas las artes, tienen un bien por fin; y el primero de los bienes debe ser el fin supremo de la más alta de todas las ciencias; y esta ciencia es la política. El bien en política es la justicia; en otros términos, la utilidad general" (Aristóteles, 1969).

Se expone en Aristóteles un asunto que, desde aquel entonces, hasta la actualidad ha suscitado controversia entre los más eminentes filósofos y juristas, y es que lo que se considera por naturaleza justo es inmutable, estático, justo desde el comienzo y justo hasta el final. Por otra par- te, lo que mediante la convención o la ley, los hombres (y mujeres) acuerdan tener por justo, es mutable y sujeto a cambio. Este enfrentamiento explana en el tema bajo análisis dos consideraciones sobre la justicia: una de ellas teológica y otra convencionalista, esto es, la concepción de lo divino, lo bueno, lo perfecto en contraste con la convención, el acuerdo al que los hombres llegan como fruto de su libertad.

Dos filósofos mucho más modernos, E. Kant (1724-1804) y J. Rawls (1921-2002), revalidan la idea de justicia predominante durante siglos para asumir, con el surgimiento de la Ilustración, una idea más coherente con la libertad del ser humano. Sostienen que la idea de lo correcto y de lo bueno debe alejarse del concepto de justicia que determine a una sociedad. Argumenta Kant que los filósofos se han extraviado al concebir la idea del bien, la felicidad, la perfección o Dios, como el principio supremo de la moral2 ${ }^{2}$. Concibe

2 Kant, Emmanuel, Crítica de la razón práctica. p. 57. Salamanca: Sígueme (1997) El motivo que ha ocasionado todos los extravíos de los filósofos respecto del principio supremo de la moral. En efecto, ellos buscaban un objeto de la voluntad para convertirlo en materia y fundamento de una ley (que luego pretendía ser el motivo determinante de la voluntad no directamente sino indirectamente por medio de aquel objeto amoldado al sentimiento de agrado o desagrado), cuando lo que hubieran debido hacer primero era investigar una ley que a priori y directamente determinara la voluntad y sólo después el objeto de conformidad con ella. Pues bien, lo mismo daba que buscaran este objeto del agrado, que pretendía proporcionar el concepto supremo del bien en la felicidad, en la perfección, en la ley moral o en la voluntad de Dios: su principio era siempre heteronomía, tenían que tropezar ineluctablemente con las condiciones empíricas para una ley moral, porque sólo por su relación inmediata respecto del sentimiento, que siempre es empírico, podían calificar de bueno o malo su 
Kant que someter la noción moral a un resultado deducido es errado, toda vez que llevaría al individuo a alienar su libertad y autonomía por creaciones heterónomas.

John Rawls también presenta críticas a la concepción teológica de la justicia. El estadounidense agrega a la discusión que la visión teológica diferencia, de manera independiente, lo que es bueno, perfecto, etc. ${ }^{3}$, de lo que es justo; de esa forma se instrumentaliza la justicia para hallar la realización de fines ajenos a ella. Rawls critica firmemente que Aristóteles y los teólogos desatiendan la igualdad como elemento configurativo de la justicia. Este autor norteamericano basa su teoría en un estado originario de igualdad, y argumenta que, para llegar a la idea de justicia, debemos abstraernos de nuestras circunstancias, imaginarnos en un estado de despojo de nuestras condiciones de vida, pensar que todos estamos en buenas condiciones mentales, de salud, todos tenemos la misma cantidad de bienes y patrimonio, todos carecemos de predicar fe alguna, tenemos las mismas condiciones étnicas, de género, opinión política.

Ahora, imaginemos que bajo esas condiciones de igualdad, a las que Rawls llama el Velo de la Ignorancia, realizáramos un

objeto en tanto motivo determinante directo de la voluntad.

3 Rawls J. (1997) Teoría de la justicia. p. 37. México: Fondo de Cultura Económica. Si se toma tal concepción como la realización de la excelencia humana en las diversas formas de cultura, tenemos lo que puede llamarse perfeccionismo. Este concepto se encuentra, entre otros, en Aristóteles y en Nietzsche. Si el bien es definido como placer, tenemos el hedonismo; si lo es como felicidad, el eudemonismo, y así sucesivamente. contrato social, esto es, eligiéramos qué principios nos gobernarían como sociedad; claro es que, una vez que hayamos firmado tal acuerdo, el azar nos pondrá en una posición social incierta, podríamos después de haberse tirado esos "dados" finalizar como integrantes de una minoría étnica, política o de cualquier índole, podríamos terminar enfermos, ateos o teístas, hombres o mujeres, nacionales o extranjeros.

Para el autor de la Teoría de la justicia, solo en ese estado podríamos hacer un contrato social justo, donde se garanticen iguales libertades políticas e iguales condiciones sociales y económicas, y de haber alguna diferencia en ellas, deberá ser solo en función de mejorar las condiciones de los menos favorecidos, es decir, si se quiere incentivar la construcción, para prohijar a las personas de vivienda, los constructores deberán ganar más, si se necesitaran más médicos para atender a la sociedad, también deberían ganar más. Las personas no se arriesgarían a escoger principios utilitaristas por la posibilidad de terminar perteneciendo a una minoría, ni elegirían principios que coarten libertades u oportunidades porque podrían resultar en la pobreza; con tanto en juego, nadie se aventuraría a arriesgar tanto.

Rawls llama a esta postura principio de diferencia. Este pretende equiparar en la sociedad la distribución asimétrica de bienes y aptitudes sin obstaculizar la prosperidad de quienes se encuentran con mejores bienes y aptitudes. Este mo delo de justicia es conocido como justicia distributiva (Rawls, 1978). Pretende una 
igualdad material, partiendo de que los integrantes de la sociedad son diferentes como individuos, y que esa diferencia es arbitraria, y debería socorrerse a quienes están en desventaja para garantizarles libertades y bienes. Este autor expone que las condiciones de una persona no son objeto de merecimiento moral, toda vez que las aptitudes, las dotes físicas e intelectuales, el esfuerzo o disciplina de las personas son circunstancias arbitrarias, por la clase social en la que nació, por su entorno, inclusive por su genética, y esta arbitrariedad no debería conllevar merecimiento moral alguno. Este principio es ampliamente aplicado en nuestra sociedad, cuando se da prelación en el ingreso a universidades públicas a personas víctimas de la violencia y minorías étnicas, en la aplicación de ley de cuotas de participación femenina en cargos públicos, y en las curules a etnias indígenas y de afrodescendientes.

Otro tipo es la justicia distributiva que tiene como fuente normativa la misma Constitución Política que, basada en la solidaridad, pilar de nuestro Estado social de derecho ${ }^{4}$, permea en el ámbito infra constitucional estos deberes; es una justicia donde a los iguales se les trata como iguales y a los desiguales se les trata como a desiguales.

4 Art. 1. "Colombia es un Estado social de derecho [...] fundad[o] en el respeto de la dignidad humana, en el trabajo y la solidaridad de las personas que la integran y en la prevalencia del interés general.

Art. 366 "El bienestar general y el mejoramiento de la calidad de vida de la población son finalidades sociales del Estado. Será objetivo fundamental de su actividad la solución de las necesidades insatisfechas de salud, de educación, de saneamiento ambiental y de agua potable..."
La justicia retributiva ha sido la que, tal vez a través del tiempo, ha tenido menos transformaciones, y grosso modo consiste en que a un actuar se asigne una consecuencia proporcional; usualmente se utiliza como consecuencia ante el acaecimiento de delito. La concepción de la justicia como una retribución proporcional al delito cometido tiene como antecedente afamado la Ley del Talión. El delito se concibe como una ofensa a la sociedad, a una armonía creada. El Estado es el titular del ius puniendi, este tiene la autoridad de castigar. Este modelo de justicia es familiar a los sistemas criminales de una extensa mayoría de los países del mundo, por organizaciones como la Corte Penal Internacional y varios tribunales ad hoc, como el tribunal para la ex Yugoeslavia y el Tribunal de Nüremberg.

En el Estado social de derecho colombiano, las penas buscan la protección de la sociedad, la prevención del delito y, principalmente, la resocialización del sujeto responsable del hecho punible (Constitucional). En el ámbito internacional, la Corte Penal Internacional dispone de penas como la reclusión que no exceda 30 años, y excepcionalmente la reclusión perpetua, multa, decomiso de bienes procedentes de la comisión del crimen ${ }^{5}$;

Estatuto de Roma, Artículo 77: Penas aplicables. La Corte podrá, con sujeción a lo dispuesto en el artículo 110, imponer a la persona declarada culpable de uno de los crímenes a que se hace referencia en el artículo 5 del presente Estatuto una de las penas siguientes: La reclusión por un número determinado de años que no exceda de 30 años; o La reclusión a perpetuidad cuando lo justifiquen la extrema gravedad del crimen y las circunstancias personales del condenado. Además de la reclusión, la Corte podrá imponer: Una multa con arreglo a los criterios enunciados en las Reglas de Procedimien- 
cuando se han cometido múltiples crímenes, habrá una pena para cada delito y otra común, para todos los crímenes. Las penas impuestas por la Corte Penal Internacional tienen como finalidad prever y poner fin a la impunidad sobre los crímenes más graves de trascendencia para la comunidad internacional (Estatuto de Roma, Preámbulo).

Sin embargo, exclusivamente el castigo no es un medio idóneo para los fines propuestos por la pena, máxime cuando estos mecanismos implican coartar múltiples derechos fundamentales a un individuo. Han surgido dudas sobre la legitimación del Estado para interponer penas. La necesidad, proporcionalidad o idoneidad de la pena son constantes en el debate. Algunas posturas que defienden la necesidad de la pena, sostienen que la víctima no ha tenido culpa alguna en el hecho, pero lo ha padecido por el delito cometido por un individuo y al ser este castigado, la víctima obtiene su resocialización. El delito una vez consumado desequilibra la relación víctima-victimario, poniendo a este último en una posición dominante (Fletcher, 2000, p. 57). Por lo que la función del castigo es restablecer la igualdad entre autor y víctima que ha sido rota por el delito (Sánchez. J. M. S., 2008, p. 168).

Por otra parte, una parte de la doctrina entiende la sanción como la imposición y ejecución de una pena, justificada simple-

to y Prueba; El decomiso del producto, los bienes y los haberes procedentes directa o indirectamente de dicho crimen, sin perjuicio de los derechos de terceros de buena fe. mente por necesidades de la víctima. No obstante, esto se comprende como una venganza institucionalizada, encubierto bajo un manto de supuesta racionalidad (Sánchez J. M., 2008).

Ahora, función preventiva especial y general de la pena presenta yerros lógicos. Inicialmente, la función preventiva especial de la pena pretende que la pena cumpla una función sobre hechos futuros hipotéticos, antes que sobre lo ya acaecido. El profesor Claus Roxin puntualiza esta posición, coligiendo que:
"La teoría de la prevención especial no es idónea para justificar el Derecho penal, porque no puede delimitar sus presupuestos y consecuencias, porque no explica la punibi- lidad de delitos sin peligro de repetición y porque la idea de adaptación social forzosa medi- ante una pena no contiene en sí misma su legitimación, sino que necesita de fundamentación jurídica a partir de otras consid- eraciones." (Roxin pp17, 2008).

Sobre la finalidad conocida como la prevención general, que tiene por más eminente exponente a Feuerbach, se intenta motivar a la sociedad en general a adecuar su conducta a la norma. Esta finalidad acarrear convertir al Estado como una fuente de terror, el cual, para la finalidad preventiva general, deberá intimidar, castigando tan fuerte como le sea posible. Se instrumentaliza de esta forma al individuo, tomando su libertad como mecanismo de enseñanza para la sociedad, ciertamente 
transgrediendo su más íntimo derecho fundamental: su dignidad.

La responsabilidad en la comisión de un delito, vincula la comprensión de esta conducta con un juicio moral, que supone endilgar culpa al actor. Por lo que la ley retributiva condensa aquella "moralidad común por medio de la evaluación de las transgresiones y condenando a los transgresores a través de procesos institucionales que se acercan a la emociones colectivas y actitudes reactivas hacia el delito" (Pickard, 2015, p. 670). La concepción resocializadora del delincuente toma fuerza entonces, al entender al infractor, como un sujeto incapaz de convivir en sociedad, que requiere ser formado para erigirse como sujeto del derecho. (Quirós, 2010, p. 2)

El castigo solo encontraría razón, si se fundamenta en el propósito de acondicionar la escala axiológica de la persona humana que ha delinquido y la reclusión, tendría sustento racional, solo si responde a la necesidad de apartarlo de la sociedad para evitar que por su condición actual no presente idoneidad para convivir en sociedad. La pena está justificada por la reincorporación del individuo a la sociedad, coincide con los derechos y deberes de la colectividad y los del individuo, adquiriendo la pena un interés constructivo. No obstante, hay que sujetarse al realismo antropológico del delincuente, debe este atender a la voluntad resocializadora, vinculando a la sociedad a tal fin, como co-responsable del bienestar de sus individuos (Roxin, 2008, p. 327).
Por último, la historia nos presenta una idea de justicia que incorpora a la víctima como protagonista de la solución del conflicto, y alude al propósito indemnizatorio y reparador del daño sufrido por la víctima a causa del victimario. La posición histórica sobre la reparación del daño, como forma de aplicar justicia ante un hecho criminal, ha marcado, desde hace unas décadas, un nuevo paradigma en el derecho penal contemporáneo. Sin embargo, esta visión de la justicia se puede observar desde tiempos remotos. Los griegos antiguos, por su revolucionaria forma de pensar para aquella época ${ }^{6}$, exhiben algunos antecedentes de este tipo de justicia.

En el Fedón, Platón narra las últimas conversaciones con Sócrates, en las postrimerías de la vida de este último, antes de someterse a morir por los efectos de la cicuta y así pagar a la justicia de los hombres, y acuciado por su conciencia y por el delito cometido, Platón y Sócrates discuten sobre la permanencia del alma después de la muerte; sostiene Platón que quienes cometieron delitos en vida, sus almas se dirigen al Tártaro, y agrega Sócrates, que luego la corriente los lleva próximos al lago Aqueronte, donde gritan y llaman, rogando e implorando perdón a quienes ellos lastimaron e hirieron, y así se les permita aproximarse al lago, para

\footnotetext{
Russel B, the History of Western Philosophy. Simon $\varepsilon$ Schuster, New York. "Nothing is so surprising or so difficult to account for as the sudden rise of civilization in Greece. Much of what makes civilization had already existed for thousands of years [...] but certain elements had been lacking until the Greeks supplied them [...] they speculated freely about the nature of the world and the end of life, without being bound in the fetters of any inherited orthodoxy"
} 
finalizar con su sufrimiento y de no ser perdonados, serán de nuevo arrastrados al Tártaro y su sufrimiento se prolongará hasta disuadir a sus víctimas. Esta posición preponderante de las víctimas en las decisiones sobre la sanción del victimario, es característica de la justicia restaurativa (Córdoba, 2006). El profesor inglés, J. Braithwaite, sostiene que "la justicia restaurativa significa restaurar o recuperar a las víctimas, significa un sistema de justicia penal más enfocado en las víctimas, además de que significa restaurar a los transgresores y a la comunidad" (Braithwaite 2001 p. 96).

La reparación $n^{7}$ propende al fin utópico de indemnizar a la víctima, esto es, dejar sin daño, pero pocas conductas no dejan sobre la víctima un daño, una impresión indeleble. Sin embargo, si con la aproximación a la reparación del daño, se cumplen, en gran medida, los fines de la pena, ergo, la imposición de la pena no responderá a criterios absolutos de necesidad, atenuando la sanción penal en situaciones específicas (Rubio, 2015, p. 96).

\section{CONCEPTO DE JUSTICIA TRANSICIONAL}

El presente análisis sobre la justicia genéricamente considerada, las modalidades y tipologías, en las que el concepto de justicia se puede comprender, fueron el preludio para tomar consciencia sobre la característica abstracta de la temática. "La justicia transicional, que debe estar orientada hacia la consecución de la reconciliación, lo que implica entre otros

RAE. Reparar, renovar o volver a poner algo en el estado o estimación que antes tenía. aspectos que esta debe contribuir a evitar la división social y la conflictividad a partir del fortalecimiento de la democracia" (Rincón., 2016); sin embargo, analizar y concretar el concepto de justicia transicional será el siguiente propósito.

Primero se precisarán los elementos integrantes del concepto de justicia transicional, para así estudiar si esta modalidad de justicia está abarcada por alguna de las acepciones antes mencionadas de justicia, o tal vez, se encuentra en relación sincrética con teorías distintas o se constituya a sí misma como una concepción independiente y sui géneris de comprender la justicia. Tomando como marco conceptual la definición lograda, trazaremos historiográficamente los orígenes internacionales y colombianos de la justicia transicional.

Desde mediados de los años noventa, el término justicia transicional comenzó a usarse por Neil Kritz (Kritz, 1995), para afianzarse a comienzos del nuevo milenio. (Bell, 2008). El término justicia transicional es polivalente, por tener variedad de significados, que dependen, además de las "características de los mecanismos específicos que aparecen en esos momentos de cambio político, sino también de los contextos sociales, políticos y culturales, y de las perspectivas desde las cuales se construyen aquellos sentidos" (Sánchez G. I., 2013, p. 140).

En momentos de estabilidad política, la ley es garante de estabilidad del statu quo, pero en tiempos de conflicto, la ley mantiene el statu quo bélico e imposibilita el 
cambio. El tránsito, es la consecuencia de un contexto donde confluyen diferentes sujetos sociales para la creación de la ley, como un producto del cambio político ${ }^{8}$ (Teitel, 2000, p. 3).

La profesora Ruti Teitel (2000) concibe la justicia transicional como la justicia asociada al contexto y a las circunstancias políticas, donde el ideal universal de justicia debe ser desestimado para lograr el fin social de transitar hacia un sistema más liberal democrático. Entiende la profesora argentina la justicia transicional como un producto del voluntarismo político, como aquel resultado del acuerdo que las fuerzas sociales alcanzan para transitar del conflicto a la paz. Se vislumbra en esta posición concordancia con algunas de las concepciones de lo justo expuestas en el capítulo pretérito, al construir el significado de la justicia como la convención que resulta de las voluntades humanas.

Gabriel Ignacio Gómez Sánchez expone sobre los intereses que colisionan en las sociedades abocadas a la transición que "...se relaciona con el conflicto entre las necesidades políticas percibidas en un determinado contexto y los valores normativos de justicia". Esta tensión se presenta especialmente entre la presión política de resolver el conflicto y los reclamos sociales por la aplicación de los lineamientos de justicia preestablecidos en el sistema penal, los cuales, por lo general, están compuestos por una visión retributiva.

Teitel, Ruti, Transitional Justice. Oxford University Press. 2000
La tensión anterior exhibe el enfrentamiento de dos ideales filosóficos de justicia, cuya contraposición se había advertido anteriormente. Hablamos de un enfrentamiento entre idealistas, siguiendo la tradición liberal occidental, quienes persisten en "limitar la política mediante el derecho y defender un modelo universal y normativo de justicia transicional que conduzca al fortalecimiento de la democracia y del Estado de Derecho [... J Dicho de forma más simple, la fuerza del poder debe someterse a la racionalidad del derecho" (Kritz, 1995). Y por otra parte, los llamados realistas, quienes conciben la justicia y el derecho como consecuencia del contexto político imperante en aquel tiempo y lugar.

Con todo, el tránsito no acaba en el concepto per se, sino en la ejecución. La justicia transicional está compuesta por múltiples mecanismos que deben ponerse en práctica, tales como "procesos penales, de depuración y de reparación que tienen lugar después de la transición de un régimen político a otro"9 (Elster, 2006); sin embargo, se debe aclarar, que la definición del profesor noruego, considera estos mecanismos como actuaciones ex post, obviando que estas herramientas constituyen el tránsito en sí mismo, no una consecuencia de él.

En suma, una concepción de la justicia transicional de excepcional importancia es la elaborada por las Naciones Unidas, como máximo organismo mundial, quie-

Elster, Jon. Rendición de Cuentas: la justicia transicional en perspectiva histórica. Ira Edición. Buenos Aires: Katz 2006. 
nes han seguido de cerca los procesos de paz acaecidos en la historia de la humanidad, en países como el Congo, Kenia, Liberia, Sierra Leona, Togo, Uganda, Afganistán, Nepal, Colombia, Guatemala, Haití, Camboya, Sudan, Timor-Leste, Burundi, entre otros. Por su autoridad y proactividad en supervisar conflictos, la ONU es referente obligatorio en relación con la idea de justicia transicional.

Actualmente los procesos de justicia transicional, inclusive cuando se realizan dentro de un Estado o a causa de un conflicto interno como el colombiano, se interrelacionan obligatoriamente con un derecho globalizado en el que convergen los diferentes organismos internacionales. "la globalización del derecho y los renovados escenarios del derecho internacional hacen que en la actualidad no puedan desarrollarse procesos de transición simplemente domésticos"10 (Quinche Ramírez, 2014).

Entendiendo esta relación entre el derecho nacional e internacional, la oficina del Alto Comisionado de las Naciones Unidas para los Derechos Humanos (OHCHR) elaboró un manual de "Instrumentos del Estado de Derecho para Sociedades que han salido de un Conflicto". Tales medidas incluyen enjuiciamientos penales, estrategias de determinación de la verdad, diversas formas de reforma internacional, iniciativas de justicia local y reconciliación, y reparaciones para las víctimas (Alto

10 Quinche Ramírez y otros, La dimensión normativa de la justicia transicional, el sistema interamericano y la negociación con los grupos armados en Colombia, Anuario Colombiano de Derecho Internacional. 2014
Comisionado de las Naciones Unidas para los Derechos Humanos (OHCHR), 2008).

En el mismo sentido, el Consejo de Derechos Humanos, en el $21 .^{\circ}$ período de sesiones del 24 de septiembre de 2012, presentó informe a la Asamblea General de Naciones Unidas, sobre la "promoción y protección de todos los derechos humanos, civiles, políticos, económicos, sociales y culturales, incluido el derecho al desarrollo", donde expresa varios elementos de la concepción que tiene el organismo mundial, sobre la justicia transicional.

Al respecto el Consejo de Derechos Humanos:

[...] pone de relieve la importancia de aplicar a la justicia de transición un enfoque global que abarque toda la gama de medidas judiciales y no judiciales, como el procesamiento individual, la reparación, la búsqueda de la verdad, la reforma institucional, la investigación de los antecedentes de los empleados o funcionarios públicos, o bien una combinación apropiada de estas medidas, a fin de, entre otras cosas, garantizar la rendición de cuentas, hacer justicia, brindar vías de reparación a las víctimas, fomentar la recuperación de la normalidad y la reconciliación, establecer entidades independientes que supervisen los sistemas de seguridad, restablecer la confianza en las instituciones del Estado y promover el estado de derecho de conformidad con el derecho de los derechos humanos ${ }^{11}$.

"Consejo de Derechos Humanos, en el 21. ${ }^{\circ}$ período de sesiones del 24 de septiembre de 2012, presentó informe a la Asamblea General de Naciones Unidas, 
Se resalta la importancia de tener en cuenta el contexto, de desarrollar el derecho a la verdad por medio de mecanismos diversos a los procesos judiciales, donde converja la población. Reafirma la obligación de los Estados de procesar a los responsables de violaciones a los derechos humanos y al derecho internacional humanitario. Resalta un enfoque diferencial sobre delitos cometidos por violencia sexual y de género. Expresa que "los acuerdos de paz respaldados por las Naciones Unidas no pueden permitir jamás la amnistía por actos de genocidio, crímenes de lesa humanidad, crímenes de guerra y violaciones graves de los derechos humanos". Concibe para las víctimas de graves delitos contra la humanidad la realización de los derechos al acceso igual y efectivo a la justicia; la reparación adecuada, efectiva y rápida del daño sufrido y el acceso a información pertinente sobre las violaciones y los mecanismos de reparación. Entiende que "es preciso incorporar un enfoque de derechos humanos a los procesos de selección que forman parte de la reforma institucional" (Consejo de Derechos Humanos, ONU, 2012) para garantizar la no repetición.

Sin embargo, la Organización de Naciones Unidas clama por concebir un sentido amplio de justicia transicional, que se enfoque principalmente en las medidas que deben incorporar los Estados en sus procesos para la transición. Estima especialmente los derechos de las víc-

referente a la "promoción y protección de todos los derechos humanos, civiles, políticos, económicos, sociales y culturales, incluido el derecho al desarrollo" timas como prioritarios y las posiciona como preponderantes en los procesos transicionales. Por otra parte, mantiene una posición estática sobre el interés de castigar a los responsables de la comisión de delitos de lesa humanidad, crímenes de guerra y violaciones graves de los derechos humanos. El elemento castigo siempre ha estado presente como consecuencia para el responsable (Comisión Colombiana de Juristas, 2007); la comprensión del derecho al castigo del responsable, como componente del derecho a la justicia que tiene la víctima se refleja en el aforismo "nullum crimen sine poena", entendiendo la pena como castigo. La postura que defiende la anterior afirmación ha sido llamada doctrina de la lucha contra la impunidad, quienes sostienen que el deber de castigar es una obligación que ostenta el Estado.

De este modo lo ha hecho saber el Tribunal Penal Internacional para la ex Yugoslavia, argumentando que:
[...] los crímenes de lesa humani- dad son serios actos de violencia que dañan a los seres humanos al golpear lo más esencial para ellos: su vida, su libertad, su bienestar físico, su salud y/o su dignidad. Son actos inhumanos que por su extensión y gravedad van más allá de los límites de lo tolerable para la comunidad internacional, la que debe necesariamente exigir su castigo (Tribunal Internacional para la exYugoslavia, Caso Pros- ecutor v. Erdemovic).

Concuerda la Corte Interamericana de Derechos Humanos, al oponerse a las 
acciones tendentes a no castigar estos delitos, demostrando así:

\section{[...] la manifiesta incompatibilidad entre las leyes de auto amnistía y la Convención Americana sobre Derechos Humanos, las mencio- nadas leyes carecen de efectos jurídicos y no pueden seguir rep- resentando un obstáculo para la investigación de los hechos que constituyen este caso ni para la identificación y el castigo de los responsables, ni puedan tener igual o similar impacto respecto de otros casos de violación de los derechos consagrados en la Convención Americana|...) (CIDH caso Chumbipuma Aguirre y otros versus Perú, 2001).}

No obstante, es menester aludir al término castigo, que ha sido recurrente como derecho de la víctima, pero cuya significación ha sufrido una aparente mutación, pasando de una concepción retributiva de castigo a una menos inquisidora para el victimario. En Colombia, las negociaciones de La Habana, en su Acuerdo sobre las Víctimas de Conflicto'12 (Conversaciones), han convenido regirse por parámetros de justicia restaurativa, los cuales posicionan preferentemente a las víctimas y les otorgan la posibilidad de intervenir en la reconstrucción de sus derechos.

Mientras las Organizaciones de Naciones Unidas son un organismo carente de

12 Nuevo Acuerdo Final (tomado el 15 de julio de 2017) de: http://www.altocomisionadoparalapaz.gov.co/ mesadeconversaciones/PDF/24-1480106030.11 1480106030.2016nuevoacuerdofinal-1480106030. $\underline{\mathrm{pdf}}$ jurisdicción, la Corte Interamericana de Derechos Humanos (en adelante Corte IDH) tiene instituida la función de conocer de los asuntos relacionados con el cumplimiento de los compromisos contraídos por los Estados parte en la Convención Interamericana sobre Derechos Humanos (Humanos C. I.). Así lo ha hecho desde la entrada en vigencia de la convención, el 22 de mayo de 1979, que fue firmada el 22 de noviembre de 1969 y ratificada el 28 de mayo de 1973, por medio de la Ley 16 de 1972.

Los pronunciamientos de la Corte Interamericana y sus interpretaciones sobre los estándares y tratados sobre derechos humanos son de absoluta obligatoriedad. Esta tesis es sustentada por la Corte Interamericana de Derechos Humanos, no ha sido de pacifica aceptación, y ha sido fuertemente debatida por Perú y Venezuela ${ }^{13}$, Estados que han sostenido la postura de la negación de la obligatoriedad de los pronunciamientos del Sistema Interamericano de Derechos Humanos ${ }^{14}$, considerando la primacía de la soberanía del

13 Al ser condenado por la Corte Interamericana, en el Caso Apitz Barbera y otros ("Corte Primera de lo Contencioso Administrativo") contra Venezuela, en Sentencia de agosto 5 de 2008, el Tribunal Supremo de Justicia sostuvo la negación absoluta de la jurisdicción del sistema interamericano en una "acción de interpretación constitucional" de la sentencia de la Corte Interamericana.

14 Al ser declarada la responsabilidad internacional de Venezuela, esta vez, por la violación del derecho a la integridad personal (Art. 5.1. de la Convención) y por incurrir en tratos inhumanos y degradantes (Art. 5.2 de la Convención), en relación con el artículo 1.1 de la Convención Interamericana de Derechos Humanos, en el Caso Díaz Peña contra Venezuela, el 26 de junio de 2012, llevó a continuar la posición de desacatamiento por parte del expresidente Chávez. 
Estado sobre el derecho internacional y la supremacía de la constitución nacional de los Estados. Por otra parte, el profesor argentino Osvaldo Gozaíni argumenta que solo las opiniones consultivas y las sentencias de fondo son de obligatorio acatamiento por parte de los Estados parte, excluyendo el carácter obligatorio de las recomendaciones. La posición de la Corte IDH tiene como génesis las violaciones a los derechos humanos y la impunidad, ocurridas como consecuencia de leyes de amnistía proferidas por algunos Estados parte de la Convención. Esto resalta la particular importancia que la materia tiene para la Corte IDH y para el derecho internacional y es de gran importancia y relevancia con el caso colombiano, toda vez que rige sobre el ordenamiento jurídico colombiano.

Sobre el concepto de justicia transicional, la Corte IDH ha abordado en algunas sentencias los parámetros respecto a la prohibición de promulgar leyes de amnistía, punto final o de perdón y olvido en circunstancias de normalidad o de justicia de transición, sean aquellas normas expresas o tácitas. Esta jurisprudencia se ha mantenido uniforme durante los últimos tres lustros.

La Corte IDH rechaza vehemente y reiterativamente la adopción de las leyes de auto-amnistía, por considerarlas incompatibles con la Convención y un incumplimiento de los deberes consagrados en ella. La Corte ha conocido la problemática de las leyes conocidas como de "autiamnistía". En una primera oportunidad abordó el asunto en el Caso Castillo Páez (27 de noviembre de 1998); asimismo, en la Sentencia Caso Loayza Tamayo fechado igual al anterior y el asunto ha transitado en otros casos, como en el Caso Barrios Altos versus Perú, en Sentencia de 14 de marzo de 2001, donde dio a conocer que:
Las leyes de auto amnistía con- ducen a la indefensión de las víctimas y a la perpetuación de la impunidad, por lo que son mani- fiestamente incompatibles con la letra y el espíritu de la Convención Americana. Como consecuencia [...] las mencionadas leyes ca- recen de efectos jurídicos y no pueden seguir representando un obstáculo para la investigación de los hechos que constituyen este caso ni para la identificación y el castigo de los responsables.

El magistrado Antonio A. Cançado Trindade, compartiendo la decisión unánime de la Corte IDH en el Caso Almonacid Arellano y otros contra Chile Sentencia de septiembre 26 de 2006, acudió al voto razonado para expresar que "dichas autoamnistías, aunque basadas en instrumentos "legales" -leyes, decretos leyes, u otros- son la propia negación del Derecho, son verdaderamente una aberración jurídica". En otra sentencia sobre el Perú, en el Caso La Cantuta contra Perú. Sentencia de noviembre 29 de 2006, el magistrado Sergio García Ramírez, usando el mismo medio, agregó que "la existencia formal de las leyes de amnistía [...] dentro del ordenamiento jurídico peruano constituye per se un incumplimiento del artículo 2 de la Convención". En este mismo sentido, el magistrado ad hoc Roberto de Figueiredo Caldas concibió la operación de leyes de 
auto amnistía como una "violación de los derechos a las garantías judiciales y a la protección judicial, estatuidos en los artículos 8.1 y 25, y el deber de adoptar disposiciones de derecho interno (artículos 1.1 y 2), en beneficio de los familiares de las víctimas desaparecidas y de la persona ejecutada" (Caso Gomes Lund y otros (Guerrilha do Araguaia) contra Brasil, Sentencia de noviembre 24 de 2010).

La prohibición de aceptar leyes de auto amnistía en casos de violaciones a los derechos humanos conduce a reforzar el derecho a la verdad, al conocer las circunstancias que dieron lugar al delito, a garantizar a las víctimas el acceso a mecanismos para conocer la verdad y para la aplicación de justicia, y a adoptar herramientas de no repetición y castigo de los victimarios.

La Corte IDH refuerza los elementos que durante este capítulo se han trabajado, concibiendo estos parámetros solo un poco más estrechamente que la Organización de Naciones Unidas. Con todo, tenemos un marco conceptual amplio para entender las directrices que diferentes organismos internacionales y doctrinantes entienden de la justicia de transición.

La justicia transicional es el mecanismo de reconciliación aplicado por las sociedades que han padecido sistemáticas violaciones a los derechos humanos y al derecho internacional humanitario por parte de uno o varios actores bélicos. Dicha justicia busca comprender el origen del conflicto, tiene como objetivo superar las situaciones del mismo y transitar hacia una sociedad más democrática y pluralista, mediante instrumentos de aplicación de justicia transitorios y no permanentes para resolver un conflicto bélico en particular. Se enfoca principalmente en los efectos de la guerra sobre las víctimas, su acompañamiento y el reconocimiento de ellas ante la sociedad en el proceso de cambio, y a que estén sujetas a ser recompuestas en sus derechos e indemnizadas material y espiritualmente.

\section{TIPOLOGÍA DE LA JUSTICIA TRANSICIONAL}

Analizaremos consecuentemente la clasificación del concepto de justicia transicional que hemos estudiado, considerando la acepción alcanzada en la presente investigación heurística, porque dicho tipo de justicia "permite en especial un margen de flexibilidad para el logro de sus objetivos de reconciliación y paz, así como la garantía del mayor nivel posible de derechos de las víctimas"15.

En consecuencia, el marco conceptual para comparar el modelo de justicia que propone la transición lo haremos con los modelos genéricos examinados en el primer capítulo. Fruto de esto podremos concluir una de tres situaciones: una primera donde concibamos que los lineamientos de la justicia transicional se bastan en un concepto pretérito de justicia, y que la alusión a la transición sea solo una adecuación de aquel modelo a

15 Gustavo Rojas Páez y Andrés Mauricio Guzmán Rincón. ¿Más allá de la justicia correctiva?: potencialidades de la restitución de tierras en la superación de los conflictos armados. En: Revista Opinión Jurídica, Vol. 15, N² 29, p. 27 ISSN 1692-2530

- Enero-junio de 2016. 
unas circunstancias especiales; una segunda situación con la que nos podremos enfrentar es el contraste de la primera, entender la justicia transicional como un concepto de justicia que se sustenta por sí mismo y en el que, por sus elementos específicos y especiales, no se relaciona con concepción alguna, que tiene fundamentos propios que la hacen una idea sui géneris de justicia. Por último, una visión sincrética de justicia podría ser el resultado de nuestra investigación en el presente capítulo. Sincrética por confluir en el concepto de justicia transicional varias ideas de justicia antes mencionadas y la interrelación de ellas devenga en lo que conocemos por justicia transicional.

Conocemos que la justicia transicional es una opción política a la que se arriba como consecuencia de un contexto social, en el que las diferentes fuerzas sociales desean transformar un statu quo bélico y transitar hacia un estado donde impere la armonía pluralista y democrática. No podría resultar la aprehensión de la justicia transicional de una concepción a priori y ex ante de justicia. Por el contrario, es una decisión política que se toma con base en unos sucesos precedentes.

Por lo tanto, su génesis no está fundamentada en la libertad de los sujetos en optar por ideales éticos que gobiernen sus actos. La justicia transicional es una justicia ex post facto, producto de la necesidad de la sociedad de transitar hacia la paz, es necesaria porque no se encuentran instrumentos diferentes, unos menos aflictivos que consigan llevar la sociedad del terror de violaciones sistemáticas a los derechos humanos y al derecho internacional humanitario hacia una próspera democracia. Por lo anterior, debe la justicia transicional ser empleada como una herramienta terminal para lograr el fin deseado, por no existir otro medio político, jurídico o militar para alcanzarlo.

Las medidas jurídicas constituyen el andamio desde donde se construirá la transición; el objetivo de las leyes en periodos de estabilidad debe transformarse para permitir el tránsito; según la profesora Teitel (2000), las leyes son los cauces por donde deben correr las ideas políticas convenidas para acabar el conflicto. Estas leyes son los resultados de la convención de las fuerzas sociales orientadas a la transición. En el marco de la necesidad de acabar el conflicto se encuentran las voluntades y se pacta un proyecto legal, lo que lleva a reflexionar sobre la adaptación de la justicia transicional en alguna de las concepciones voluntaristas de justicia. Sin embargo, la necesidad niega la libertad, presupuesto para comprender la voluntad como motor del actuar humano.

Los valores iusnaturalistas en los que se motivan los derechos, en especial los derechos humanos, son producto de una concepción ético racional del ser humano y se concretan o positivizan en normas rectoras. Estos derechos humanos constituyen una cultura de las libertades que en su conjunto inspira su sistematización en sentido jurídico-positivo en instrumentos internacionales, donde se reconocen derechos intransigibles y de imperativo cumplimiento, derechos que, más que convenidos, son impuestos por 
la fuerza de la razón. Con estos elementos (la necesidad y el sistema internacional de derechos humanos) se observa un conflicto que limita el arbitrio del actuar político. Por ello vemos en organizaciones como las Naciones Unidas y la Corte IDH un concierto de parámetros para la ejecución de la justicia transicional que son ciertamente límites materiales a la voluntad de las fuerzas sociales que pretenden el tránsito, recordando a Manuel Quinche Ramírez en el sentido de que los "renovados escenarios del derecho internacional hacen que en la actualidad no puedan desarrollarse procesos de transición simplemente domésticos" (Huertas, 2014).

La justicia transicional es enfocada hacia las víctimas del conflicto; son ellas quienes ocupan la posición más desventajosa en el contexto bélico: han sufrido lesiones y afectaciones en el ámbito material, esto es, en sus bienes, su hogar y su patrimonio. Pero, más grave aún, las víctimas han sufrido afectaciones en el campo psíquico y espiritual; estas son huellas de difícil reparación, y que las lleva a cargar con la condición de víctima, inclusive cuando ya se han reparado las consecuencias que el delito tuvo en el aspecto material.

María Paula Saffon (Saffon, 2011, p. 14), en el prólogo del libro titulado: Justicia Transicional, afirma que:

$[\ldots]$ en las últimas décadas [...] ha ocurrido una importante evolución normativa que se ha traducido en la consagración de unos derecho cada vez más vinculantes de los que son titulares las víctimas de crímenes atroces. Esta evolución ha sido dinamizada por cuatro tendencias: el derecho internacional humanitario, el derecho penal internacional, el derecho internacional de los derechos humanos y los principios del derecho internacional orientados a combatir las violaciones a los derechos humanos y al derecho internacional humanitario.

La importancia que ostentan las víctimas en un proceso de justicia transicional exige incorporar modelos de justicia entendida como la verdad, que es un instrumento para sustentar los hechos de las acusaciones o procesos judiciales, pero es, a la vez, y por sí, la aplicación misma de justicia ${ }^{16}$, "el valor de la verdad es sacrosanto para las víctimas y la sociedad" (Mani, 2011).

La reparación pretende recomponer a la víctima en sus condiciones de vida y resocializarla, esto es, una reparación adecuada, efectiva y rápida del daño sufrido; sin embargo, toda reparación es utópica, no se puede volver a recomponer lo que ya se ha descompuesto. Y para a los victimarios se consideran importantes las teorías sobre el castigo expuestas con antelacióna, a saber, la teoría retributiva y la restaurativa.

El castigo es un término amplio e indeterminado en el ámbito internacional, que ha implicado infligir sufrimiento o dolor mediante la constricción de derechos como la libertad de manera proporcional

16 "Algunos sostienen la idea de que las omisiones de verdad van más allá de la justicia penal y retributiva y se dirigen a la justicia restaurativa" David A. Crocker. 
y humana, y que considera razonable en el sentido de que resocialice al sujeto infractor. También este fin es alcanzable por medio de otras formas de concebir el castigo, como lo es el mecanismo de justicia entendido como restaurativa, que pretende reparar a la víctima económica y psicológicamente; esta reparación debe provenir del victimario conforme al "principio general del derecho según el cual el responsable de un daño o agravio debe repararlo o compensarlo." (Corte Constitucional, 2014). No podría propenderse a la reconciliación si quienes buscan eximir las culpas son terceros ajenos a la victimización. "Cuando las reparaciones se plasman en castigos económicos para los individuos responsables y el Estado, pueden ser un mecanismo de disuasión igual de efectivo que los castigos penales, incluso tal vez más efectivos" (Mertel, 2005, p. 155).

No obstante, optar por el mecanismo de la justicia restaurativa, por la retributiva o por ambas puede hacer parte del voluntarismo político y del contexto social, así como de la intensidad y gravedad de los delitos y, además, del lapso trascurrido entre el proceso de justicia el acaecimiento del hecho victimizante. Así, a mayor gravedad del delito, menor período de tiempo y permanencia de las secuelas; la sociedad buscará inclinarse mayoritariamente hacia la opción retributiva, sin prescindir de la función indemnizatoria. Sin embargo, el castigo no se debe centrar necesariamente en uno $u$ otro sistema de justicia; este será una medida que debe ser pactada por las fuerzas sociales ${ }^{17}$.

17 Núremberg, es el caso por antonomasia donde
No obstante, el modelo de justicia distributiva pareciera gobernar la posición de considerar a las víctimas con un enfoque especial en el proceso; las desigualdades originadas en la guerra han afectado y desequilibrado a las víctimas, excluyéndolas de la dinámica social. Por esto, se alude a unas políticas diferenciales para compensar favorablemente a quienes han sido aminorados por el conflicto.

Todo esto nos invita a concebir la justicia transicional, no como una justicia sui géneris, tampoco a enmarcarla dentro de un modelo específico de justicia. La justicia transicional está compuesta por variedad de ideas de justicia que se complementan para hacer frente a una realidad social y proporcionan un horizonte teórico para lograr un tránsito social hacia la reconciliación.

\section{CONCLUSIONES}

La justicia transicional es un término heterocompuesto donde confluyen varias acepciones de justicia para afrontar un periodo de violaciones sistemáticas a los derechos humanos y al derecho internacional humanitario; en ella se aprecian varias ideas de justicia: iusnaturalistas, sobre los derechos humanos; consecuencialistas, por ser una justicia ex post facto; distributiva, por propender a equilibrar las desigualdades que el estado de guerra ha ocasionado restaurativa, por tener una finalidad reparadora de las víctimas.

imperó el castigo concebido como retribucionismo. Por otra parte, en el proceso de pacificación de Sudáfrica se optó (en medio de críticas) por la justicia restaurativa. 
Todo lo anterior nos lleva a comprender la justicia transicional como una justicia que sincretiza diferentes ideas de concebir lo justo, para hacerla más funcional y adaptada a la realidad.

Lograr el éxito en un proceso de paz como el colombiano demanda coherencia entre la concepción teórica y la práctica de la transición, y que el líder que guíe la transición tenga la habilidad política de unificar el espíritu del Estado, de congregar a todos los sectores de la sociedad en un interés común. No se podrán cumplir los fines esenciales del proceso de transición, si se construye un acuerdo que sea ajeno a los distintos sectores sociales, lo que llevaría una ausencia de idoneidad de los medios para lograr el fin. Un acuerdo en cuya estructuración hayan intervenido voluntades particulares difícilmente producirá un compromiso moral erga omnes.

En consecuencia, en el caso colombiano referente al acuerdo de paz firmado entre el Gobierno y las FARC, el mejor instrumento para calificar el acuerdo es la justicia transicional por ser un mecanismo jurídico sinónimo de justicia alternativa, evolutiva y transitoria para solucionar un problema en concreto; alternativa, porque no es una generalidad social; evolutiva, porque es un instrumento innovador específico, y transitoria, porque es fugaz y momentánea, utilizada solo para solucionar un problema concreto o, haciendo un símil con el control constitucional explicado por el profesor David Mendieta (Mendieta, 2017), es una herramienta de garantismo y justicia para alcanzar una mejor convivencia.

\section{REFERENCIAS BIBLIOGRÁFICAS}

Alexy, R. (2015). Dignidad Humana y Proporcionalidad. Bogotá: Universidad del Rosario.

Alto Comisionado de las Naciones Unidas para los Derechos Humanos (OHCHR). (2008). Instrumentos del Estado de derecho para sociedades que han salido de un conflicto. (13/10/2017) Disponible en: http://www.ohchr. org/Documents/Publications/ReparationsProgrammesSP.pdf

Aristóteles. (1969). La política. Madrid: Austral.

Bertrand, R. (1972). The History of Western Philosophy. New York: Simon \& Schuster.

Bell, C. (2008). On the law of peace. Oxford: Oxford University Press.

Comisión Colombiana de Juristas (2007). Principios internacionales sobre impunidad y reparaciones. Bogotá: Opciones Gráficas.

Comisión Colombiana de Juristas. (2007). Principios internacionales sobre impunidad y reparaciones. Bogotá: Opciones Gráficas.

Convención Interamericana de Derechos Humanos, Parte II - Medios de Protección. Capítulo VI sobre los Organismos Competentes, Artículo 33.

Corte Constitucional de Colombia, (1992). Sentencia T-401 de 1992. [Magistrado Ponente: Eduardo Cifuentes Muñoz].

Corte Constitucional de Colombia (2014), Sentencia C-180 2014). [M.P. Alberto Rojas Ríos]

Corte Interamericana de Derechos Humanos (14 de Marzo de 2001). Sentencia Caso Chumbipuma Aguirre y otros vs. Perú.

Elster, J. (2006). Rendición de cuentas: la justicia transicional enperspectiva histórica. Buenos $\mathrm{Ai}-$ res: Katz.

Estatuto de Roma, Preámbulo. (s.f.). 
Gómez Sánchez, G. (2013). Justicia transicional "desde abajo": Un marco teórico constructivista crítico para el análisis de la experiencia colombiana. Co-Herencia, Vo. $10 \mathrm{~N}$. 19, 137-166.

Grocio, H. (1625). Prolegómenos del derecho de guerra y paz. Madrid: Reus.

Rojas-Páez, G. y Guzmán-Rincón, A-M. (2016). ¿Más allá de la justicia correctiva?: potencialidades de la restitución de tierras en la superación de los conflictos armados. Opinión Jurídica, Vol. 15, ․․ 29, p. 21-41.

Kritz, N. (1995). Transitional Justice: How Emerging Democracies Reckon with Former Regimes. Washington D.C.: The United States: Institute of Peace.

Mani, R. (2011). Justicia transicional. Bogota: Siglo del Hombre Editores: Universidaddelos Andes, Pontificia Universidad Javeriana, Instituto Pensar.

Mendieta, D. (2017). La acción de inconstitucionalidad en Colombia: ¿puede la corte constitucional establecer límites al ejercicio ciudadano de esta acción? Universidad Complutense de Madrid. Recuperado el 28 de julio de 2017, de: http://eprints.ucm.es/43045/1/T38873.pdf

Mertel. (2005) Truth in a box: the Limits of Justice through Judicial Mechanisms. Oxford: Intersentia.

Quinche Ramírez, M. F. (2014). La dimensión normativa de la justicia transicional, el sistema interamericano y la negociación con los grupos armados en Colombia. Anuario Colombiano de Derecho Internacional, Vol. 7, p. 113-159.
Quirós, D. Z. (2010). Justificación del castigo e inflación penal. Universidad de Palermo, (14/10/2017) Tomado de: http://www.palermo.edu/Archivos content/derecho/pdf/Justificaciondel-castigo-e-inflacion-penal-Prof-ZysmanQuiros.pdf

Rawls, J. (1978). Teoría de justicia. México: Fonde de Cultura Económica.

Roxin, C. (2008). Fundamentos político-criminales del Derecho Penal. Buenos Aires: Hammurabi.

Rubio, M. B. (2015). Reflexiones sobre justicia penal restaurativa. Derecho Penal Internacional Contemporáneo, N. ${ }^{\circ}$ 53, p. 93-118.

Russel, B. (1946). The History of Western Philosophy. Nueva York: Simon \& Schuster.

Sánchez, J.-M. S. (2008). ¿Nullum crimen sine poena? Sobre las doctrinas penales de la "lucha contra la impunidad" y del "derecho de la víctima al castigo del autor". Derecho Penal y Criminología. Vol. 29, N 86-87. p. 149-171.

Sandel, M. (2013). Justicia ¿̇hacemos lo que debemos? Bogotá: Random House Mondadori.

Teitel, R. (2000). Transitional Justice. New York: Oxford University Press.

Tribunal Internacional para la exYugoslavia. (1998). Caso Prosecutor v. Erdemovic.

Universidad de los Andes, Pontificia Universidad Javeriana, Instituto Pensar. (2011). Justicia transicional. Bogotá: Siglo del Hombre. 